\title{
Географическое образование
}

УДК 551.594

DOI: https://doi.org/10.26456/2226-7719-2021-1-93-104

\section{ШКОЛЬНОЕ ИЗУЧЕНИЕ ГЕОГРАФИИ ОПАСНЫХ ЯВЛЕНИЙ (НА ПРИМЕРЕ ГРОЗЫ) И ФОРМИРОВАНИЕ ОПЫТА ОБЖ}

\author{
Н.Б. Прокофьева ${ }^{1}$, Е.В. Осипова ${ }^{2}$
}

${ }^{1}$ ФГБОУ ВО «Тверской государственный университет», г. Тверь

${ }^{2}$ Санкт-Петербургский государственный университет, г. СПб.

Цель исследования - экспериментально-практическая разработка для школьного курса географии 6 кл. по теме «Атмосфера» на примере изучения опасных атмосферных явлений (грозы) с элементами ОБЖ. Грозовые явления в школьной географии не изучаются. Это актуализирует данное исследование и определяет его новизну.

Ключевые слова: методика преподавания географии, география опасных явлений, грозовая активность.

Предметная область исследования - сочетание физической географии (изучение атмосферы и опасных явлений) и основ безопасной жизнедеятельности (ОБЖ) в школьной географии. Актуальность исследования и методической разработки определен рядом программных положений и важным воспитательным значением темы - формированием навыков ОБЖ.

Для методического исследования выбрана проблемная тема изучения опасных природных явлений (на примере гроз). В данной теме важно было объединить географические умения, имеющие «теоретические» и практическое значение. Грозовые явления очень опасны для жизни, поэтому важно ввести в географию элементы ОБЖ. Определено содержание базовой компетенции, реализация которой возможна в рамках изучаемой темы - формирование первичных умений анализа опасного природного явления (грозы). Сущность нашей разработки - научить школьников пользоваться методами пространственного анализа с обращением к карте. Для этого разработаны: урок с элементами практического занятия, задания и вопросы по картам, задания и вопросы разных типов.

Вопросы изучения опасных природных явлениях (на примере гроз) в полной мере соответствуют требованиям Стандарта основного

\author{
(С) Прокофьева Н.Б., \\ Осипова Е.В., 2021


общего образования ${ }^{1}$ на всех уровнях освоения - личностном, метапредметном и предметном.

Главное умение, которое необходимо сформировать - это опыm (владение) географического изучения опасных природных явлениях (на примере гроз). Из примерной программы географии выбираем несколько предметных умений, которые можно сформировать при изучении темы:

1) Использовать различные источники географической информации (картографические, статистические, текстовые, видео- и фотоизображения, компьютерные базы данных) для решения различных учебных и практико-ориентированных задач: выявление географических зависимостей и закономерностей на основе результатов наблюдений, на основе анализа, обобщения и интерпретации географической информации объяснение географических явлений и процессов (их свойств, условий протекания и географических различий);

2) расчет количественных показателей, характеризующих географические объекты, явления и процессы;

3) составление простейших географических прогнозов; принятие решений, основанных на сопоставлении, сравнении и/или оценке географической информации).

При этом главными считаем следующие умения:

1. географическая оценка грозовой активности и опасности (на уровне районов и локальных мест),

2. ориентация в локальном грозовом пространстве и безопасное поведение (и помощь другим).

\section{Знания для формирования умений:}

1. Представление о грозовых явлениях в атмосфере и правила безопасного поведения

2. Параметры оценки грозовой активности в мире, стране, регионе

3. Правила работы с картами (чтение карт, анализ карт)

4. Основные аспекты пространственной организации/развития и параметры их оценки (территориальные различия и территориальная структура региона по грозовой активности на его территории (ареалы/зоны, районы повышенной грозовой активности, коридоры и оси, центры).

\footnotetext{
${ }^{1}$ Приказ Минобрнауки России от 17 декабря 2010 года № 1897 «Об утверждении и введении в действие федерального государственного образовательного стандарта основного общего образования» (ред.2014 г.). URL:

http://mosmetod.ru/files/dokumenty/prikaz_1897_1.doc.
} 
Итак, формирование базовой общеобразовательной компетенции при изучении опасных природных явлений (на примере гроз) в школьном курсе географии (6 класс) возможно в разной форме и сочетанием разных методов: урок-беседа (с объяснением нового материала) с выполнением аналитических и прогнозных заданий/задач, решением тестов, проведением внеклассного мероприятия - игры-тренинга для формирования умения ориентироваться в локальном пространстве во время грозы для выбора безопасного временного местонахождения.

Урок с элементами практического задания «Гроза как опасное природное явление и географическая оценка грозовой активности» Цель: сформировать представление об опасном природном явлении (грозе), выполнить картографический анализ грозовую активность мира, России, региона.

Задачи:

обучающие:

- овладение основами географического изучения опасных природных явлений (на примере гроз);

развивающая:

- формировать умение использовать различные источники географической информации, вовлекать учащихся в самостоятельную работу частично-поискового и исследовательского характера;

- формирование целостного мировоззрения;

- определять понятия, устанавливать аналогии, причинно-следственные связи, делать выводы;

воспитывающая:

- развитие осознанного и ответственного отношения к собственным поступкам;

- усвоение правил безопасного поведения в чрезвычайных ситуациях.

Тип урока: комбинированный.

Оборудование: компьютер (ноутбук), проектор, видеоролики «Как вести себя во время грозы», «Уроки безопасности. Гроза».

Технологическая карта урока

\begin{tabular}{|c|c|c|}
\hline Этап & Деятельность учителя & $\begin{array}{c}\text { Деятельность } \\
\text { учащихся }\end{array}$ \\
\hline $\begin{array}{l}\text { Организационный } \\
\text { момент. Проверка } \\
\text { отсутствующих на } \\
\text { уроке. } \\
\text { (1 мин.) }\end{array}$ & $\begin{array}{l}1 . \quad \text { Осуществляет } \\
\text { проверку готовности } \\
\text { учеников к уроку }\end{array}$ & \\
\hline
\end{tabular}




\begin{tabular}{|c|c|c|}
\hline $\begin{array}{l}\text { Проверка знаний и } \\
\text { умений }\end{array}$ & $\begin{array}{l}\text { Проводится проверка } \\
\text { знаний по пройденной } \\
\text { теме }\end{array}$ & $\begin{array}{l}\text { Выполняют задание на } \\
\text { карточках }\end{array}$ \\
\hline $\begin{array}{l}\text { Вводная беседа. (2 } \\
\text { мин.) }\end{array}$ & $\begin{array}{l}\text { Вводит учеников в } \\
\text { тему урока, } \\
\text { актуализирует задачи }\end{array}$ & $\begin{array}{l}\text { Открывают учебник и } \\
\text { готовятся к изучению } \\
\text { нового материала }\end{array}$ \\
\hline $\begin{array}{l}\text { Изучение } \\
\text { темы } \\
\text { (30 минут) }\end{array}$ & $\begin{array}{l}\text { 1. Понятие гроза } \\
\text { 2. Распределение } \\
\text { грозовой активности } \\
\text { 3. Просмотр } \\
\text { видеороликов }\end{array}$ & $\begin{array}{l}\text { Фиксируют основные } \\
\text { понятия } \\
\text { закономерности }\end{array}$ \\
\hline $\begin{array}{l}\text { Этап рефлексии } \\
\text { учебной } \\
\text { деятельности на } \\
\text { уроке } \\
2 \text { минуты } \\
\end{array}$ & $\begin{array}{l}\text { 1. Предлагает } \\
\text { рефлексию } \\
\text { результатов работы. }\end{array}$ & $\begin{array}{l}\text { Осуществляют } \\
\text { рефлексию }\end{array}$ \\
\hline $\begin{array}{l}\text { Домашнее задание } \\
2 \text { минуты }\end{array}$ & $\begin{array}{l}\text { 1. Задаёт домашнее } \\
\text { задание }\end{array}$ & $\begin{array}{l}\text { Воспринимают, если } \\
\text { необходимо, задают } \\
\text { вопросы. }\end{array}$ \\
\hline
\end{tabular}

Ход урока:

I.Организационный этап (проверка готовности класса к уроку)

II.Проверка и закрепление знаний по пройденной теме.

III. План урока:

1. Понятие гроза

2. Распределение грозовой активности

Учитель: Ребята, сегодня мы будем изучать такое природное явление, как гроза. Что такое гроза и чем она сопровождается? Гроза бурное ненастье с дождем, громом и молниями. Грозы связаны с развитием кучево-дождевых облаков, со скоплением в них большого количества электричества. Многократные электрические разряды, происходящие в облаках или между облаками и землей, называются молниями. Гроза обязательно сопровождается раскатами грома и порывами ветра.

Учитель: что-то о грозах вам известно из повседневной жизни, например, признаки приближающейся грозы. Я предлагаю вам из указанных признаков выбрать только правильные.

\section{Приближается гроза, если:}

а) дует легкий ветерок;

б) становится тихо и душно;

в) сильно печет солнце;

г) на горизонте скопление мощных кучево-дождевых облаков; 
д) в воздухе накапливается влага;

е) моросит мелкий дождь;

ё) понижается температура воздуха;

ж) ветер дует порывами, резко меняет направление;

3) ветер поднимает тучи пыли;

и) солнце светит, но не греет.

Ответы: б, в, г, д, ж, з.

Учитель: вам представлен график рис.1. В каком месяце больше всего гроз и с чем это связано?

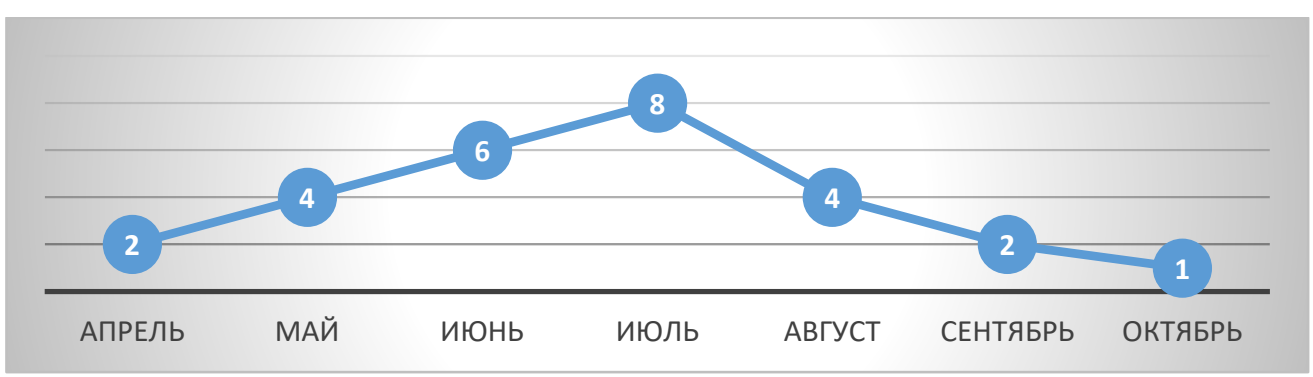

Р и с. 1. Среднее количество гроз по месяцам по гидрометеостанциям Тверской области за период 1988-2018 гг. [5]

Самое больше количество гроз приходится на июль, что связано с высокой активностью солнца.

Учитель: сейчас мы будем рассматривать распределения грозовой активности на территории мира, России, а также нашего региона, Тверской области.

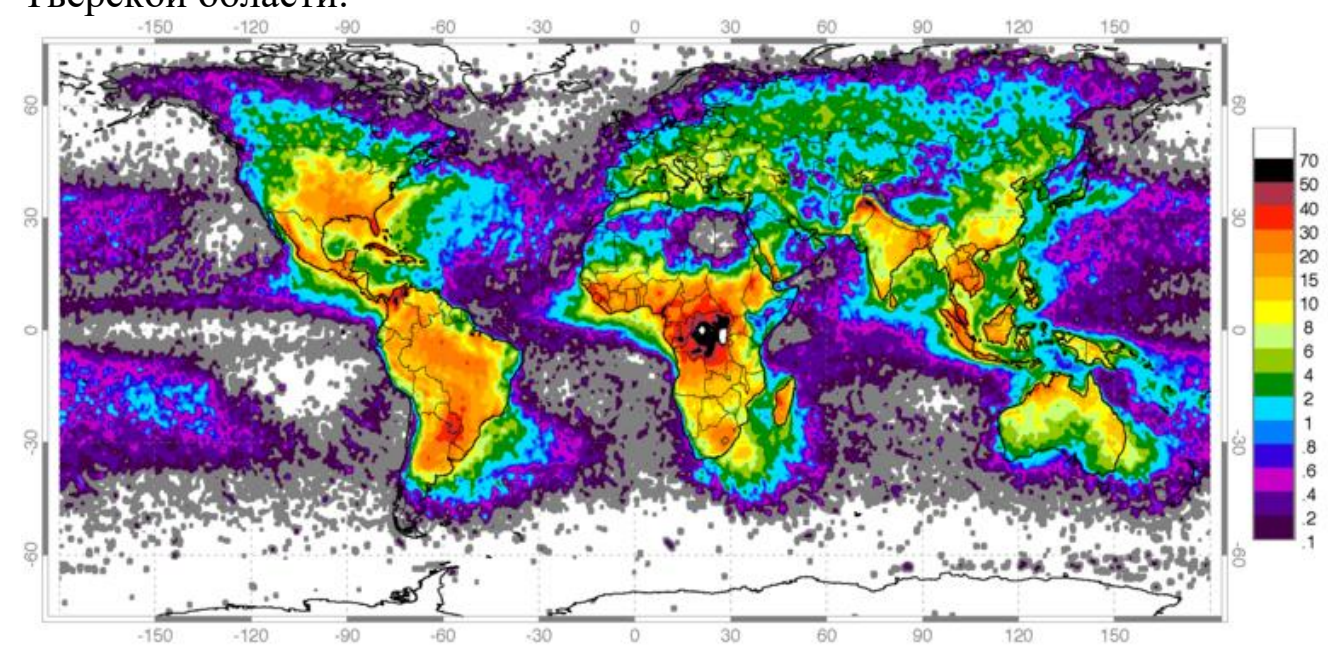

Р и с. 2. Распределение молниевых вспышек на поверхности земного шара. Результаты наблюдений с борта спутников OTD и LIS. Источник: https://ikfia.ysn.ru/priroda-grozovoj-aktivnosti/ [2,3] 
По поверхности планеты грозы распределяются неравномерно. Над океаном гроз наблюдается приблизительно в десять раз меньше, чем над континентами. В тропической и экваториальной зоне (от $30^{\circ}$ северной широты до $30^{\circ}$ южной широты) сосредоточено около 78 \% всех молниевых разрядов. Максимум грозовой активности приходится на Центральную Африку. В полярных районах Арктики и Антарктики и над полюсами гроз практически не бывает.

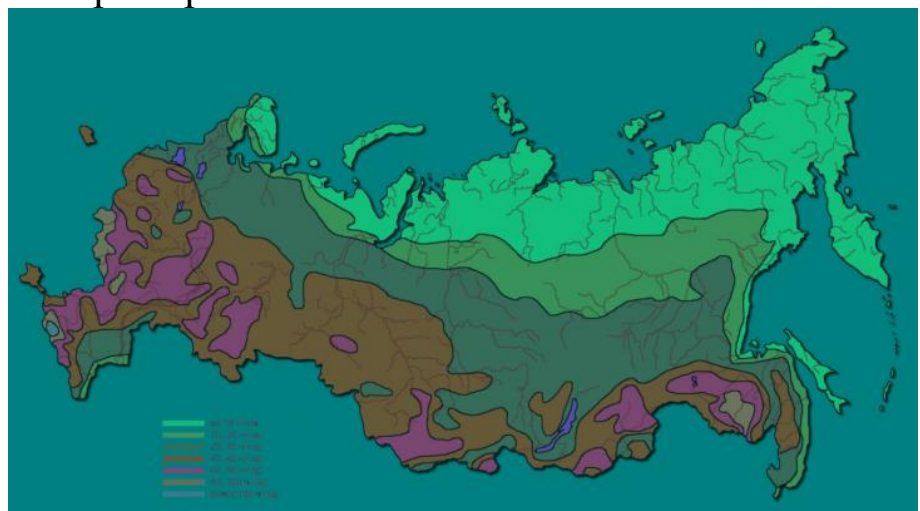

Р и с. 3. Грозовая активность на территории РФ

Источник: https://ezetek.ru/poleznye-stati/karta-grozovoj-aktivnosti

Мы видим (рис.3), что в северной части Российской Федерации интенсивность грозовой деятельности минимальна и составляет менее 10 грозовых часов в году. Но чем южнее находятся объекты, тем выше интенсивность грозовой деятельности, и в некоторых регионах составляет более 100 грозовых часов в год.

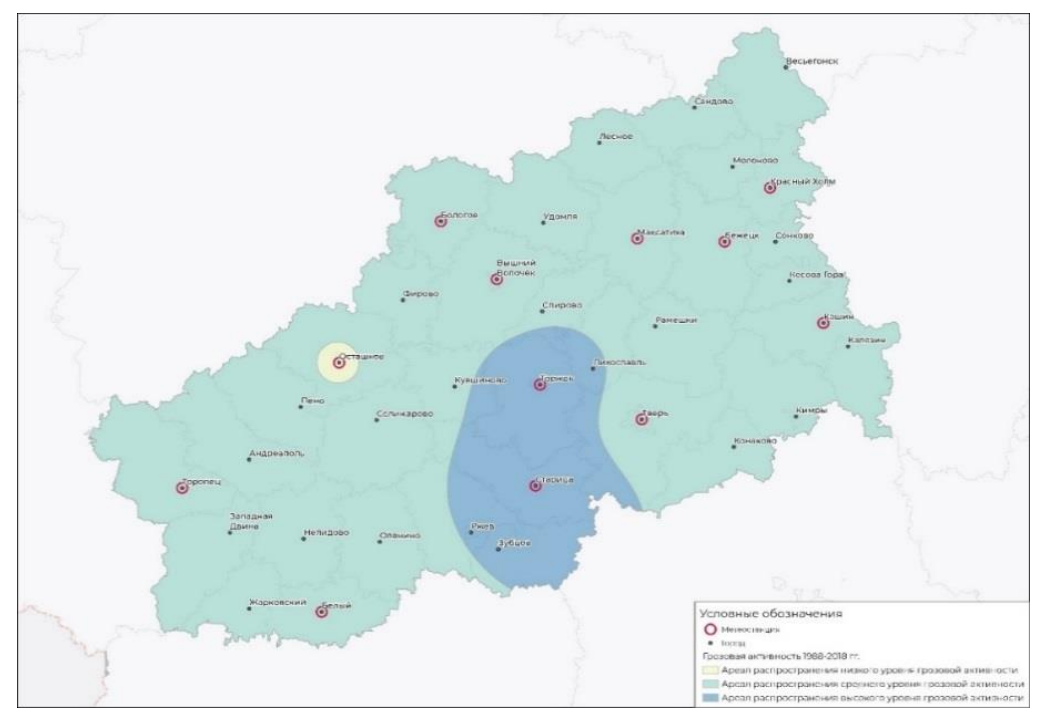

Р и с. 4. Грозовая активность на территории Тверской области за период 1988-2018 гг. [4] 
На территории Тверской области (рис.4) мы видим неравномерное распределение грозовой активности. Можно выделить «очаг» высокой грозовой активности, это метеостанции Торжок и Старица, а также низкой на метеостанции Осташков.

Показ видеороликов «Как вести себя во время грозы», «Уроки безопасности. Гроза»

\section{Закрепление.}

Разгадать электронный кроссворд.

Домашнее задание: разработать памятку «Как вести себя во время грозы» с помощью родителей.

Практическое задание (домашнее задание)

Практическое задание «Как вести себя во время грозы»

\begin{tabular}{|c|c|}
\hline $\begin{array}{c}\text { Правила поведения при грозе } \\
\text { в/на ... }\end{array}$ & Действия \\
\hline \multicolumn{2}{|l|}{ В здании } \\
\hline На улице & \\
\hline $\begin{array}{l}\text { На улице в технике (машина, } \\
\text { мотоцикл и т.п.) }\end{array}$ & \\
\hline
\end{tabular}

\section{Географические задания для школьников}

Разработаны задания разного содержания по основным географическим элементам: факты, номенклатура, понятия, географические закономерности и взаимосвязи, и др.

- Фактологические:

1) Кто проводит наблюдения за грозами? Гидрометеоцентр.

2) В какие сезоны обычно бывает гроза (рис.1)? Весна, лето, осень. Апрель - октябрь.

- Понятийные:

1) Что считается опасным явлением?

2) Что такое гроза? Гроза-атмосферное явление метеорологического характера, при котором в мощных кучево-дождевых облаках и между облаками и землёй возникают сильные электрические разряды - молнии, сопровождающиеся громом. Как правило, при грозе выпадают интенсивные ливневые осадки, нередко град, и наблюдается усиление ветра, часто до шквала.

3) Что характерно для грозы? Раскаты грома и порывы ветра.

- Причинно-следственные (логические):

1) Объясните, почему бывает гроза? Она происходит, когда между мощными дождевыми облаками или между облаками и землёй возникают многократные электрические разряды - молнии. Электрические искры, пробивая воздух, мгновенно разогревают его, он резко расширяется, производя сильный шум, и мы слышим удар грома. 
2) От чего зависит появление данного явления: высокая или средняя влажность воздуха у земли; восходящее движение воздуха при низком атмосферном давлении; высокая температура у поверхности земли; постепенное ускорение движения подъема влажного воздуха по мере роста кучевого облака; трение ледяных кристаллов в верхней части облака, а также трение его водяных капель вызывают ионизацию воздуха; основной очаг небольшой грозовой тучи присоединяет соседние облака, и грозовая туча увеличивает свою площадь; прохождение холодного атмосферного фронта или тёплого атмосферного фронта может вызвать интенсивную конвекцию воздуха, и образование грозы, в то время, когда в других областях циклона гроз не наблюдается.

3) Какие могут быть последствия? Разрушение зданий, сооружений; пожары, гибель людей и животного мира; повреждение линий электропередач; затопление территорий.

- Проблемные, в том числе о географических закономерностях:

1) Установите по картам районы повышенной грозовой активности в Тверской области (для учеников предложены карты разных периодов, например, рис. 4)? Период 1988-1997 гг.: Торжок, Старица. 1998-2007 гг.: Старица, Торжок, Максатиха, Красный Холм, Бежецк. 2008-2018 гг.: Торжок, Старица, Тверь.

2) Эти зоны территориально устойчивые? Зоны высокой грозовой активности Тверской области устойчивы лишь на метеостанциях Старица, Торжок.

3) Зоны повышенной грозовой активности образуют единый цельный район/коридор или изолированы друг от друга? Зоны высокой грозовой активности образуют единый цельный район.

- Методические:

1) Что надо сделать, чтобы быть в безопасности во время грозы? Во время грозы стоит избегать открытой местности. Во время грозы избегайте воды. Очень опасно во время грозы разговаривать по мобильному телефону. При грозе желательно избавиться от металлических предметов.

- Технико-экономические:

1) Какие меры защиты предусмотрены от гроз? Молниеотводы, заземление электроэнергии в помещениях, генераторы.

Внеклассное мероприятие - тренинговая игра для формирования умений ориентироваться в локальном грозовом пространстве и навыка безопасного поведения

Учитель: Добрый день, ребята! Какая сегодня погода за окном? Какая погода вам больше всего нравится и почему?

Звучит песня «У природы нет плохой погоды».

Учитель: Домашнее задание, которое я вам задавала (памятка безопасного поведения при грозе) сегодня очень вам поможет [1]. Вы 
будете спасаться от грозы в разных ситуациях и локациях (поле, лес, дом, речка, машина).

Учитель: Давайте вспомним правила поведения при опасном природном явлении, как гроза.

Учитель поочередно выписывает правила на доске, которые называют дети. Далее называет каждое, а дети, которые согласны с данным правилом. поднимают руки, учитель фиксирует количество рук. В итоге получается ТОП-3 правил, которые знают дети от своих родителей.

Учитель: сейчас мы разберем одну из ситуаций для примера. Вы находитесь в чистом поле, есть два понижения рельефа (1 - песчаная почва, 2 - глина). В каком месте вы присядете и обхватите голову руками?

Стоят 3 таблички: 1- поле, 2 - песчаная почва, 3- глинистая почва. выбрали.

Ребята распределяются рядом с табличками, которые они

Учитель: спаслась группа, которая выбрала песчаную почву, ведь она быстрее пропускает воду и не задерживает ее. А теперь примените все свои полученные ранее знания и спасайтесь. У всех будет по 5 жизней (вырезанные сердечки). За каждый неправильный выбор вы отдаете одно сердце.

1-я ситуация:

Открытая местность (поле), стоят несколько одиноких высоких деревьев (высокий большой дуб и липа), имеется овраг на расстоянии от дерева 100 м и небольшая яма на расстоянии 300 м от дерева. Где вы укроетесь?

Карточки: дуб, липа, овраг, яма.

Ребята, которые выбрали дуб, липу и овраг отдают по «сердцу». Правильный выбор - «яма» (рис.5).

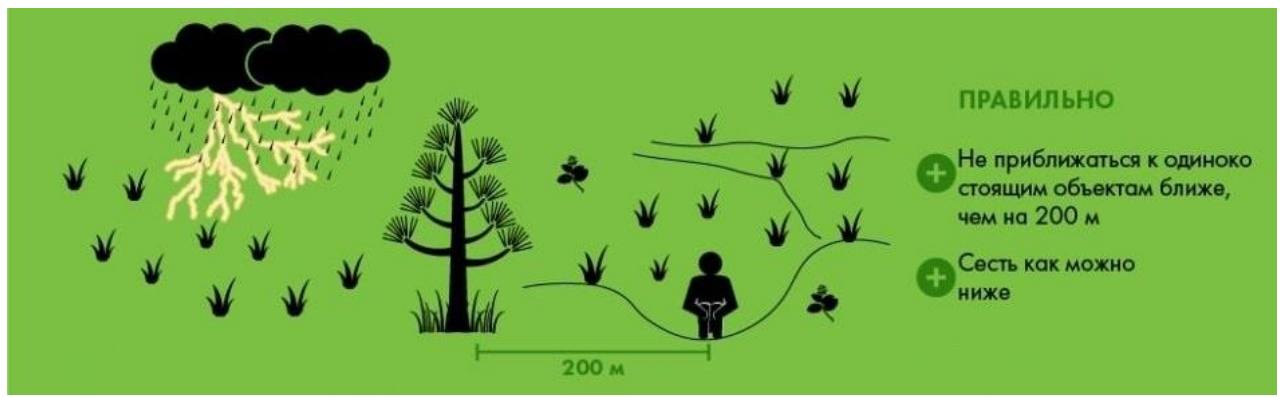

Р и с. 5. Безопасность на открытой местности

Источник: https://fireman.club/statyi-polzovateley/pravila-bezopasnosti-vovremya-grozyi/[1] 


\section{2-я ситуация:}

Вы находитесь в лесу, есть как высокие деревья, так и кустики. Холодно и темно, вы будете разжигать костер? Где вы сядете в позе эмбриона, чтобы переждать грозу?

Карточки: костер, высокие деревья, кустики.

Ребята, которые выбрали костер и высокие деревья отдают по «сердцу».

Правильный выбор - «кусты» (рис.6).

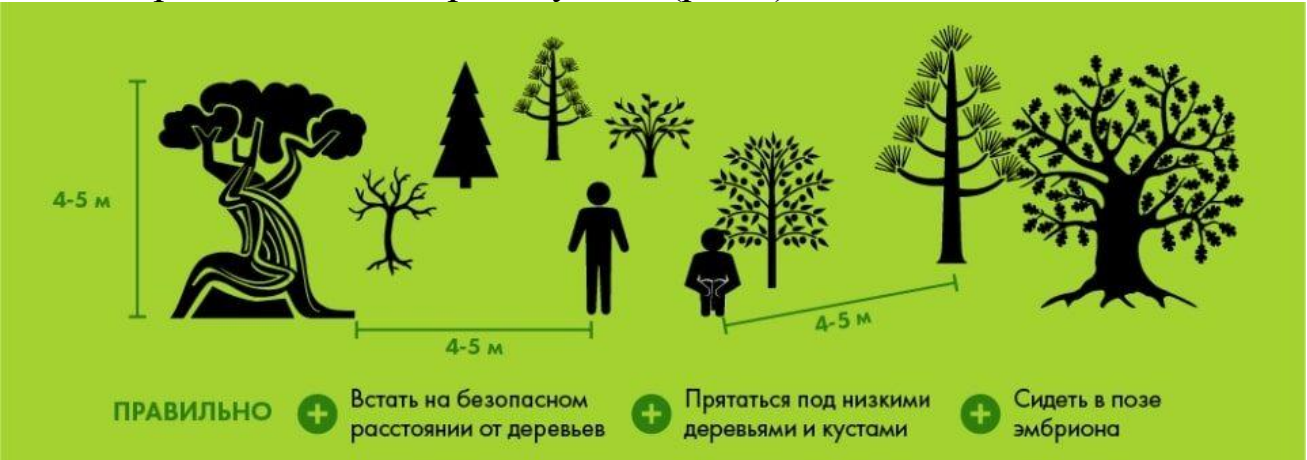

Р и с. 6. Правила поведение в лесу при грозе

Источник: https://fireman.club/statyi-polzovateley/pravila-bezopasnosti-vovremya-grozyi/[1]

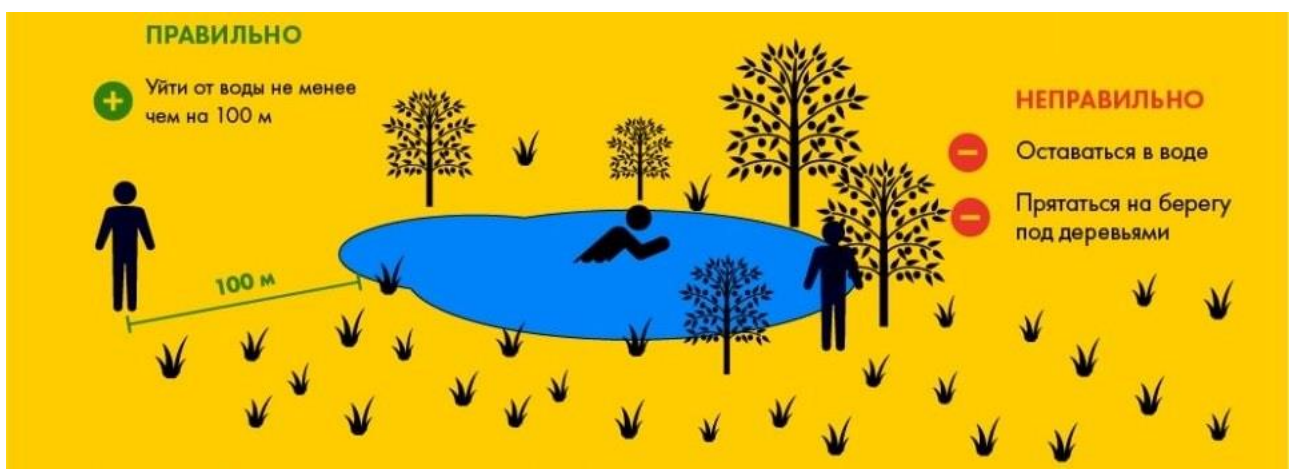

Р и с. 7. Безопасность при грозе у воды

Источник: https://fireman.club/statyi-polzovateley/pravila-bezopasnosti-vovremya-grozyi/ [1]

Разводить костер не безопасно, ведь дым притягивает разряды молний.

3-я ситуация:

Вы отдыхаете на берегу озера с палатками, высокие и могучие дубы растут и маленькие липы растут на расстоянии 200 м.

Таблички: озеро, палатка, дуб, липа.

Ребята, которые выбрали озеро, палатка и дуб отдают по «сердцу». 
Правильный выбор [1] «липа» (рис.7): нужно отойти от воды менее через на 100 м, оставаться в воде запрещено, т.к. она является отличным проводником электричества, в палатке тоже не стоит пережидать грозу. Под высокими деревьями тоже, к тому же дуб является деревом, в которое чаще всего бьет молния (54\%), а липа имеет маленький процент (2\%), притом дерево еще маленькое.

\section{4-я ситуация:}

Выберите вещь, которая не притянет к вам молнию.

Таблички: мокрая одежда, телефон, зонт, велосипед, цветы, ключи.

Правильный ответ «цветы».

Итак, ребята, возможно у кого-то из вас осталось одно «сердце» и одна жизнь, поэтому прежде, чем принять решение, хорошенько подумайте.

\section{5-я ситуация:}

Вас гроза настигла в машине, вы остановились на обочине. Ваши действия: будете звонить в спасательные службы; возьметесь за ручку двери; закроете окна; будете слушать радио?

Таблички: телефон, ручка авто, окно, радио.

Правильный ответ: закрыть окна.

Учитель: Примите мои поздравления, кто выжил при таком опасном природном явлении, как гроза. Хочу вам сказать, больше читайте правила безопасности, никто не знает, когда и где они вам пригодятся. Дети, вам понравилось? До скорой встречи.

Экспериментально-практическое исследование для одной из фундаментальных тем физической географии (Атмосфера, 6 кл.) показало важную роль практических занятий для формирования умения географического анализа опасного природного явления (грозы) и воспитания безопасного поведения в грозовых условиях.

\section{Список литературы}

1. Правила безопасности во время грозы. Сайт: fireman.club. Клуб пожарных и спасателей. URL: https://fireman.club/statyipolzovateley/pravila-bezopasnosti-vo-vremya-grozyi/.

2. Природа грозовой активности. На сайте Института космофизических исследований и аэрономии им. Ю.Г. Шафера Сибирского отделения Российской академии наук (ИКФИА CO PAH, Якутск). URL: https://ikfia.ysn.ru/priroda-grozovoj-aktivnosti/.

3. Прекрасные и опасные метеорологические явления. Презентация. URL: https://en.ppt-online.org/253859. 
4. Прокофьева Н.Б., Осипова Е.В. Характер грозовой активности на территории Тверской области за последние 30 лет// Вестник Тверского ун-та. Серия География и геоэкология. Вып. 4 (32), 2020. С. 95-108.

\title{
SCHOOL STUDY OF THE GEOGRAPHY OF HAZARDOUS EVENTS (ON THE EXAMPLE OF A THUNDERSTORM) AND FORMATION OF A SAFE LIFE EXPERIENCE
}

\author{
N.B. Prokofieva ${ }^{1}$, E.V. Osipova ${ }^{2}$ \\ ${ }^{1}$ Tver State University, Tver \\ ${ }^{2}$ Saint-Petersburg State University, Saint-Petersburg
}

The purpose of the study is experimental and practical development for a 6th grade school geography course on the topic "Atmosphere" on the example of studying dangerous atmospheric phenomena (thunderstorms) with elements of life safety. Thunderstorms are not studied in school geography. This actualizes this research and determines its novelty.Key words: teaching methods of geography, geography of dangerous phenomena, thunderstorm activity.

Keywords: teaching methods of geography, geography of dangerous phenomena, thunderstorm activity.

\section{Об авторах:}

ПРОКОФЬЕВА Наталья Борисовна - кандидат физикоматематических наук, доцент кафедры физической географии и экологии ТвГУ, e-mail: prokofjevanat@mail.ru.

ОСИПОВА Екатерина Васильевна - выпускница факультета географии и геоэкологии ТвГУ (2020), студентка магистратуры СПбГУ, e-mail: caterina.osi@yandex.ru. 